\title{
Interacciones sin nombre. Un caso emblemático: Ne me quitte pas (Cirque du Soleil) ${ }^{1}$
}

\author{
Óscar Quezada Macchiavello \\ (Universidad de Lima)
}

Recibido: 4/4/2014

Aprobado: 11/5/2014

\begin{abstract}
Resumen: El presente artículo esboza una teoría tensiva, figural, de la interacción, que se opone y complementa con la teoría narrativa y figurativa propuesta por Eric Landowski. Esta última propone una taxonomía de las interacciones dispuesta en el cuadrado semiótico; aquella, mientras tanto, respetando dicha taxonomía, la dispone en intervalo(s) sobre los que se deslizan cursos vectoriales. Estos últimos dan cuenta de cuatro zonas de tensión: desprogramación, reprogramación, desajuste, reajuste. Esa irrupción de la gradualidad permite imaginar una gama de «interacciones sin nombre». La mencionada propuesta teórica se pone a prueba en el análisis de las cómicas peripecias de una parodia de la célebre canción de Jacques Brel, Ne me quitte pas, puesta en escena por el Cirque du Soleil's Varekai.
\end{abstract}

Palabras clave: interacciones / intervalo / desprogramación / reprogramación / desajuste / reajuste / tensividad / Landowski

\section{Namless interactions. An emblematical case: Ne me quitte pas (Cirque du Soleil)}

Summary: The present article proposes an approach of a tensive, figural theory of interaction, which oposes and complements with the narrative and figurative theory proposed by Eric Landowski. The latter theory proposes a taxonomy of interactions displayed in the semiotic square. Meanwhile, the tensive theory, respecting Landowski's taxonomy, displays it in intervals upon which vectorial directions slide. This directions account for four areas of tension: deprogramming, reprogramming, disadjustment, readjustment. This irruption of graduality allows us to imagine a wide set of «nameless interactions». This theoretical proposal is put to the test in the analysis of the comic incidents in a parody of the reknowned song by Jacques Brel: Ne me quitte pas, in an scene played as a part of Cirque du Soleil's Varekai.

Key words: interactions / interval / deprogramming / reprogramming / disadjustment / readjustment / tensivity / Landowski

1 El presente artículo antecede al presentado en Contratexto 21. Fue publicado en De Oliveira, A. C. (Ed.). As interações sensíveis. São Paulo: Estaçao das Letras e Cores. 
Las más bellas civilizaciones comienzan por la risa. ¿Qué objeto tiene callarlo?

Michel Serres²

\section{Cuerpo y conocimiento}

$\mathrm{M}$ ichel Serres coloca al mimo, o más bien al acto de miconocimiento. Previamente critica el sensualismo de la Edad de las Luces y constata, en ese empeño, que el camino de los sentidos al entendimiento (de lo sensible a lo inteligible, diríamos nosotros) suele borrar todo resto del cuerpo o reducirlo a la función de transportar las cinco terminales periféricas. Esa crítica alcanza también al empirismo lógico y a las ciencias cognitivas, que proponen una génesis del conocimiento sin cuerpo. Por un lado, el célebre camino de la sensación al entendimiento se desvía hacia un refinamiento sensorial típico de la alta cultura; pero, en simultáneo, anestesia y desafina a la mayoría ${ }^{3}$. Por otro lado, «nadie vio jamás el camino detallado del color azul a la palabra azul, que ya no tiene nada de azul, de los sentidos al concepto; los receptores bioquímicos y los mensajeros intersinápticos nunca condujeron a un pensamiento ileso de proteína y de carga eléctrica» (Serres, 2011, p. 103).

La tesis de Serres puede resumirse así: antes que un conocimiento cierto y seguro, el resultado real de la experiencia es un raro refinamiento sensorial en medio de un mundo anestésico y depredador. Corregiríamos luego a Serres en cuanto a que no es lo estético, sino lo estésico lo que concluye en estética. Precisamente por eso estaríamos de acuerdo con él en que el sapiens de la sabiduría desciende del de la sa-

2 2011, p. 103.

3 Nihil est in intellectu quid non prius fuerit in sensu, es la máxima recogida de la tradición medieval. Al terminar ese tránsito iniciado en la sensación, comprueba Serres que «la sapiencia deja sitio a la sagacidad» y que, ese camino, más que terminar en esos conocimientos canonizados por la ciencia, desemboca de facto «en un gusto refinado, en un olfato exquisito y un tacto aterciopelado, forma una vista delicada en matices, cultiva un oído musical o lingüístico sutil... en suma, construye una cultura fina o instruye en una de las bellas artes. Pero semejante desarrollo es raro: ¿cuántos a nuestro alrededor usan con felicidad la piel, el tímpano, las papilas de la lengua?, ¿cuán poco se quejan de la fealdad y del ruido que contaminan el espacio, del horror de los paisajes masacrados, de las ciudades hediondas, de un alimento del que se alaba más bien la rapidez que el sabor? ¿Qué queda finalmente de las adquisiciones sensoriales en la abstracción, las bibliotecas, las pantallas y las redes?» (Serres, 2011, p. 76). He ahí la paradoja: la hegemonía de la sagacidad sobre la sapiencia junta, en toda una forma de vida, el refinamiento sensorial con la artificiosidad y la destrucción medioambiental. 
pidez. Pero pienso que si la semiótica no quiere, como el sensualismo, quedar reducida a un mero tic académico, debe explorar a conciencia las articulaciones corporales de la estesis, asumiendo, con Serres, que no hay nada en el conocimiento que no haya estado primero en todo el cuerpo.

\section{Un plano de la expresión para las interacciones}

Nuestra pertinencia es «todo el cuerpo» interactuando con «lo otro». De ahí que una semiótica que se ocupa de esas diversas interacciones demande un plano de la expresión que, de acuerdo con Fontanille, sería la semiótica de los cuerpos-actantes (2009, p. 115). Si bien la cuestión del conocimiento, en semiótica, estaría atada a la dimensión cognitiva de los discursos, también es cierto que ese vínculo sería incomprensible sin la emergencia de la dimensión sensible encarnada en el cuerpo. El modelo de encarnación corporal productora de actos es sugerido por el mismo Fontanille: de un punto central brotan tres vectores que entran en interacción tensiva y diseñan zonas de dominio de cada uno de los tres ejes de la identidad, que remiten a tres operaciones semióticas de base: la toma de posición (por lo que se refiere al Mí-carne, instancia sensorio-motriz de referencia), la captación (en lo que atañe al Sí-ídem, instancia de los roles obtenidos por similitud y repetición) y la mira (en lo que concierne al Sí-ipse, instancia de las actitudes obtenidas por tránsito y alteridad). La hipótesis matriz es que todo actante «encarnado» se puede analizar en dos instancias por lo menos: el Mí-carne de referencia y el Sí-cuerpo propio en devenir. La identidad actancial se construye, pues, en acto. En consecuencia, el modelo de producción del acto se apoya en la interacción entre la carne y el cuerpo propio, entre el Mí y el Sí (ídem/ipse) (Fontanille, 2008, pp. 52-54).

A todo esto, reconozco y aprecio, sin duda alguna, la probada consistencia epistemológica y la validez metodológica de la semiótica de la interacción elaborada por Eric Landowski. Inquietan, eso sí, las «zonas de tránsito», los «medios caminos entre» un régimen y otro; en suma, la problemática gradualidad que parece acompañar a la reflexión elaborada magistralmente por Landowski, en especial en cuatro de sus libros ${ }^{4}$.

En principio, me pregunto si la sustitución de las líneas rectas del cua-

4 La société réfléchie (1989), Présences de l'autre (1997), Passions sans nom (2004) y Les interactions risquées (2005). La teoría a la que hace referencia este artículo se encuentra sistemáticamente expresada, sobre todo, en los dos últimos libros. En especial, la definición de los cuatro regímenes de interacción: programación, manipulación, ajuste y accidente; que corresponden, respectivamente, a lógicas de la regularidad, de la intencionalidad, de la sensibilidad y del azar. Remito al lector a dichas obras. 
drado semiótico por líneas curvas es suficiente para explicitar la prioridad de los procesos sobre el sistema. En la lectura propuesta por Landowski (2009, pp. 81-87): ¿cómo así la manipulación negaría lógicamente al accidente o el ajuste haría lo mismo con la programación? De inmediato, la imaginación teórica del autor da solución a esos aparentes impasses cuando plantea, junto a los canónicos cotejos «horizontales», otros «verticales», en virtud de los cuales una programación, recursivamente, puede condicionar a otra, lo que también sucede con los demás regímenes; además, oblicuamente, una programación puede comandar o condicionar un ajuste; o bien, uno puede ajustarse a la manera de ser de otro, a su hexis, para poder manipularlo mejor ${ }^{5}$. Esta otra sintaxis «tridimensional» incorporaría la operación de rección y daría valor operatorio a la relación entre contrarios, algo que la sintaxis fundamental canónica, «bidimensional», impedía sin más.

Esa flexible «plastificación» en profundidad del cuadrado semiótico resulta útil y legítima para encarar el problema de la gradualidad de regímenes. Sería muy pretencioso de mi parte cuestionarla. Solo busco, en este breve artículo, a partir del reconocimiento del cuerpo-actante como posible plano de la expresión de una semiótica de las interacciones y de la consecuente correlación conversa entre tensión y riesgo, ensayar otra interpretación semiótica de la gradualidad que apela, esta vez, a una representación tipo intervalo. Por cierto, esta «aventura» se suscitó en el momento en que nos pusimos a analizar un texto audiovisual preciso, paradigma de parodia, esto es, de imitación burlesca. Se trata de Cirque du Soleil's Varekai. Ne me quitte pas 6 .

La burla va dirigida a la seriedad y solemnidad con la que suelen cantar ciertas baladas los intérpretes de la chanson francesa. En la perspectiva del simulacro puesto en escena, que es la que asumimos aquí, las peripecias del cantante, sus metamorfosis gestuales, sus posturas móviles, el «sabor» que dejan sus ímpetus receptivos y emisi-

5 «Si ‘horizontalmente' (dentro del espacio de dos dimensiones del esquema), todo régimen de sentido y de interacción tiende hacia otro por implicación o por contradicción, cada uno de estos regímenes puede además regir 'verticalmente' (entre planos imaginariamente superpuestos en el espacio), es decir, recursivamente, su propia reproducción. (...) Sin embargo, aquí también las relaciones se complejizan rápidamente. Al lado de la recursividad propiamente dicha, según la cual una interacción que depende de un régimen dado comanda a otra del mismo tipo, hay también lugar para una recursividad de carácter oblicuo, o 'rección', de tal naturaleza que el funcionamiento de un régimen determinado comande o condicione la puesta en marcha de otro régimen» (Landowski, 2009, p. 91).

6 http://youtu.be/uSgViEzhieU. Se trata de una parodia circense de la célebre canción de Jacques Brel, protagonizada por Claudio Carneiro. 
vos; en suma, sus sucesivos momentos de «iconización» vehiculados por súbitas morfologías figurativas corporales parecen conjugar en acto, a distintos niveles, regímenes heterogéneos de interacción.

\section{Intervalos en curso}

Una realidad como esa lleva a preguntar si es que la programación y el accidente no podrían ser tratados como súper-contrarios que demarcarían límites en lo que sería el campo categorial de las interacciones, y si la manipulación y el ajuste no serían acaso sub-contrarios que darían lugar a la segmentación de grados en el mencionado dominio, $y$, por ende, a una gama de posibles mezclas. Dicho en términos más contundentes: la programación y el accidente, como coincidencias que son, pertenecerían al mundo del «todo o nada», «insignificancia o sinsentido», mientras que el ajuste y la manipulación, interacciones en sentido estricto, pertenecerían al del «más o menos», en el que resuena la música semiótica del «hacer sentido» y del «tener significación». En consecuencia, si asumimos esas «reglas de juego», las nociones de ajuste y de programación ampliarían su alcance: servirían para designar cuatro vectores: de la programación al ajuste, un vector de repunte: la desprogramación; del ajuste al accidente, un vector de redoblamiento: el desajuste; del accidente a la manipulación, un vector de atenuación: el reajuste; y de la manipulación a la programación, uno de aminoración: la reprogramación. Como género, el concepto de programación daría lugar a dos especies: la desprogramación y la reprogramación; asimismo, el ajuste también daría lugar a dos especies: el desajuste y el reajuste, e incluso, si pensamos en el momento final en el que el cantante persigue a muchos círculos de luz simultáneos y termina cayendo a un hueco, podríamos postular que el límite del accidente se convierte en grado para demarcar un nuevo límite, algo así como un más allá: el desbarajuste.

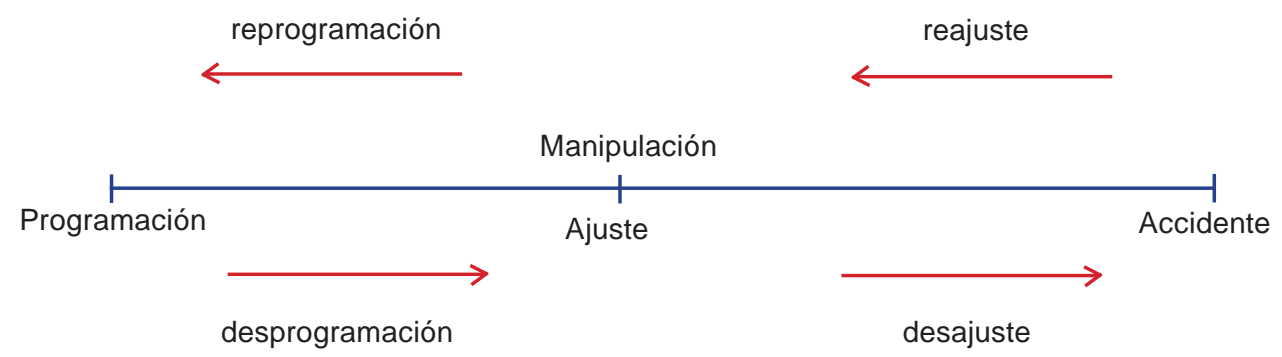


Se puede ver, en esta matriz, que el ajuste y la manipulación ocupan la misma posición, la cual cambia de sentido, y por ende de investimento semántico, de acuerdo con la dirección dominante (o con el movimiento del cursor que segmenta grados y que juega a oscilaciones entre los mismos). También se puede establecer, admitiendo una zona central de intersección, que la zona izquierda tipifica al Sí-ídem de los roles y la derecha al Sí-ipse de las actitudes. Ahora bien, la correlación conversa entre riesgo y tensión indica que, en la zona izquierda, cuyo régimen de riesgo es la seguridad total (o casi total), tendríamos el correlato actancial de un cuerpo «aburrido», laxado por la rutina y el hastío. En la medida en que el cursor se mueve hacia la derecha van aumentando el riesgo y la tensión, desde la zona donde tenemos un cuerpo no tan tenso, pero que asume riesgos limitados, hasta las sucesivas zonas de inseguridad, en las que van subiendo la «adrenalina», el pulso, la presión, hasta que llegamos a la zona del riesgo total, paroxismo de la tensión en el que el cuerpo es «secuestrado» por el evento. Queda entendido que todas las zonas del intervalo contraerían, de menos a más riesgo (ascendentemente) o de más a menos riesgo (descendentemente), re- laciones más o menos fluidas o tensas con el Mí-carne, núcleo sensorio-motor de referencia y de experiencia semiótica. En términos de modos de eficiencia, el hacer advenir, o el «llegar a», punto de partida de un recorrido ascendente, hace funcionar sin problemas los roles temáticos previstos, hasta que, gradualmente, los obstáculos se van manifestando, las complicaciones van apareciendo, los vectores del hacer querer y del hacer sentir, de la intencionalidad y de la sensibilidad, confluyen o se entrelazan mezclando y contagiando, o bien separando las competencias modales y estésicas, hasta que arribamos al punto en el que, luego de «sobrevenido» un evento, se inicia el recorrido descendente ${ }^{7}$.

Por cierto, frente a un texto complejo en el que nos vemos obligados a homologar tridimensionalmente varios intervalos de este tipo, estamos en condiciones de hacer, junto a los cotejos «horizontales», los cotejos «verticales» oblicuos, o directos (recursividades), en cuyo caso, reencontraríamos proyecciones «en profundidad», lo cual permitiría, al menos por ahora, imaginar dinámicas sinusoidales o espirales diversas. La incorporación de la rección a la sintaxis se explica por

7 Deliberadamente, hemos puesto «llegar a» y «sobrevenido» entre comillas para aludir al modo de eficiencia de las dos acciones concernidas. La reflexión sobre esos modos de eficiencia es transversal a toda la semiótica tensiva. Está perfilada en el capítulo «Centralidad del evento» y resumida en el glosario (Zilberberg, 2006, pp. 179-213, p. 460). 
diferencias de intensidad ${ }^{8}$. Así, por ejemplo, la diferencia de potencial entre ajuste y manipulación puede generar un cambio de dirección, por el cual la manipulación también se podría desajustar hacia el accidente, o el ajuste se podría reprogramar hacia la programación. Asimismo, un régimen de interacción lo suficientemente fuerte puede saltar «en profundidad» afectando a cualquier otro.

\section{Ne me quitte pas}

Por praxis enunciativa conocemos las convenciones de iluminación de la puesta en escena de los espectáculos, en particular de los llamados shows: en un ambiente oscuro, un rayo luminoso es lanzado sobre el animador, artista, cantante; en suma, showman, que ocupa el centro del escenario. Es la pre- sencia digna de ser destacada por enfoque. Se espera, pues, concentración luminosa en el protagonista foco, así como conformidad y adecuación entre los movimientos del rayo luminoso y los del protagonista.

Pues bien, este es el caso de un «cantante» de nerviosos movimientos y exagerada mímica, que con su mirada seria a lontananza, su vivaz terno entre verde y celeste, su rulo sobre la frente, su postura erguida, su palidez, el marcado movimiento de sus labios..., padecerá el drama de una interacción descoordinada (o de una no coincidencia) permanente con aquel rayo de luz, símbolo de la mirada que lo pone en el centro del espectáculo9. Por convención, esperamos el ajuste, la compulsión a que lo «normal» se repita (Sí-ídem), pero sucede el cómico espectáculo del desajuste y hasta del desbarajuste, a sa-

8 «La expresión 'diferencia de intensidad' es una tautología. La intensidad es la forma de la diferencia como razón de lo sensible. Toda intensidad es diferencial, diferencia en sí misma. Toda intensidad es 'E-E', en donde E remite por sí mismo a 'e-e' y e a ' $\varepsilon-\varepsilon$ ', etc.: cada intensidad es un acoplamiento (en el que cada elemento del par remite, a su vez, a pares de elementos de otro orden), y revela así el contenido propiamente cualitativo de la cantidad. Llamamos disparidad a ese estado de la diferencia infinitamente desdoblada que resuena al infinito. La disparidad, es decir, la diferencia o la intensidad (diferencia de intensidad) es la razón suficiente del fenómeno, la condición de lo que aparece. Novalis, con su turmalina, se aproxima más a las condiciones de lo sensible que Kant, con el espacio y el tiempo. La razón de lo sensible, la condición de lo que aparece, no es el espacio y el tiempo, sino lo Desigual en sí, la disparidad tal como se comprende y determina en la diferencia de intensidad, en la intensidad como diferencia» (Deleuze, 2002, p. 334).

9 ¿Cómo describir ese rostro o, más bien, esa máscara? Ciertamente tropezamos con un límite que dejamos ahí con el objeto de proseguir su «danza»; esto es, su «conflicto combativo, en una representación tragicómica que se pierde en el ridículo: ¡la guerra es la madre de los hombres!» (Serres, 2011, p. 139). 
ber, el continuo esfuerzo de un cuerpo hecho excéntrico, arrebatado y agitado; que, sin embargo, busca mantener una compostura (Sí-ipse) simulando incluso, por breves instantes, un «relajamiento»... hasta que «se distrae» y es oscurecido (Mí-carne).

Ante todo, estamos en condiciones de reconocer tres actantes: el cantante en escena (Ca); el operador del rayo luminoso, fuera de escena (Op); y el observador (Obs), también fuera de escena, pero, en determinado momento, incorporado icónicamente a esta como actor asistente. Ese rayo con el que juega el Op es el de la mira (o de la mirada) que apunta hacia aquello digno de ser captado y observado. A nivel actancial, Op y Obs estarían en un sincretismo posicional; pero, a nivel actorial, no necesariamente. En efecto, el que opera observa, pero, en realidad, ese último acto no lo define como actante operador. Él genera otro actante con el que puede o no coincidir posicionalmente, pero en ese rol actancial hay también otros actores: uno de ellos es el enunciatario espectador del video (observador implícito del espectáculo) y los demás son los actores representados como observadores asistentes, esto es, como «público». Aunque sea ocioso decirlo, vale recalcar que nuestra pertinencia es la observación audiovisual del texto-video, esto es, una visualidad «segunda», razón por la cual estamos ante el espectáculo de un espectáculo y resulta decisiva la participación del sujeto metaoperador, editor-director que maniobra y selecciona encuadres y ángulos de toma para crear un producto audiovisual. Para efectos de nuestro análisis privilegiaremos solamente el simulacro «en escena», asumiendo que, a nivel de metaobservación y metaoperación funciona un contrato enunciativo implícito.

Pues bien, el Op, del lado del enunciador, construye una observación que es actualizada, desde diferentes ángulos, por el público representado y por el espectador, del lado del enunciatario. Hace ser el recorrido de su mirada; o, para ser más exactos, lo hace mirar un objeto determinado. Dirige su mirada y lo dirige. De ese modo, en términos convencionales, el Ca debiera ser el blanco; el Op del rayo luminoso, el actante de control, y el Obs la fuente de las operaciones perceptivas (mira y captación).

Digo «debiera» porque no siempre, o casi nunca, es así. Recurrentemente se da una descoordinación o desajuste entre los movimientos del cantante y la mirada luminosa, de tal modo que, unas veces, el blanco queda «en blanco» $y$, otras veces, totalmente oscurecido. La circunferencia luminosa y móvil interactúa con el Ca alternando el breve enfoque convencional del cuerpo de este, con el que comienza y termina el espectáculo, con el correlativo desenfoque a la oscuridad, al círculo 
«en blanco» o a un sugerente y revelador claroscuro ${ }^{10}$.

Ahora bien, sucede que el título y el contenido mismo de la canción, en esa circunstancia, adquieren connotaciones especiales. En principio, ese «Ne me quitte pas» puede ser leído como el desesperado ruego del cantante («yo») al operador observador, $y$, por ende, al rayo de luz («tú»). Por cierto, las semejanzas entre la accidentada puesta en escena de la canción y su relato interno se pueden hacer extensivas a varios pasajes de ese relato, pues no es difícil deducir que ese tú-femenino al que se dirige el yo-masculino se equipara $\mathrm{u}$ homologa al Op. En escena vemos la presencia misma del abandono impregnada en la interacción del Ca con el haz de luz maniobrado por el Op; y, a la vez, escuchamos, bien entonado, un abandono, en tensión, enunciado en la letra misma de la canción.

Se trata, pues, de movimientos dispares que no se ponen de acuerdo; $\mathrm{o}$, más bien, que lo hacen en breves lapsos que solo sirven para contrastar lo «normal» esperado con lo «anormal» sorpresivo y producir diversos efectos cómicos que confrontan o contraponen mutuas torpezas. El Ca se esfuerza por ser mirado, por aparecer, pero el Op no necesariamente quiere mirar y lo hace desaparecer: a veces como que se distrae llevando la mirada del Obs a otros lugares y dejando desairado al $\mathrm{Ca}$; a veces este último logra ocupar la circunferencia luminosa, pero por pocos segundos: esta se vuelve a descentrar, a desviar de los gestos somáticos del cantante ${ }^{11}$. Esos gestos son, a la larga, la principal fuente de comicidad, cuyo blanco es el Obs: el control, o más bien descontrol (calculado, logrado), en la interacción del Op con los gestos corporales del Ca propicia una serie de efectos cómicos que tienen en común el modo como el Ca se esfuerza por ser mirado y el Op por hacer no mirar al Obs. En esa tensión

10 «Absorbemos tanto de la sombra como de las luces, y el conocimiento, en suma, radica en un trabajo constante en los límites de ese claroscuro» (Serres, 2011, p. 81).

11 Eric Landowski, en uno de sus más lúcidos y reconocidos ensayos, da cuenta modalmente de los juegos ópticos desencadenados por situaciones y posiciones de comunicación. Un actante S1 se encuentra en situación de «ser visto» y otro, S2, en la posición de observador, en la de «ver». En el caso que nos ocupa, el Ca quiere, a toda costa, ser visto; o bien, no quiere no ser visto. De ahí que su actitud se puede caracterizar como de «ostentación», o, incluso, de «descaro». Mientras tanto, el Obs que el Op construye, al confrontarse en términos no conformes con esas posiciones del $\mathrm{Ca}$, da lugar, alternativamente, a diversos efectos temáticos. En orden a las contradicciones: «S1 quiere ser visto/S2 quiere no ver», exhibicionismo de S1; «S1 no quiere no ser visto/S2 no quiere ver», repugnancia de S2; en orden a las contrariedades: «S1 quiere ser visto/S2 no quiere ver», desfachatez de S1; «S1 no quiere no ser visto/S2 quiere no ver», mojigatería de S2 («Juegos ópticos. Situaciones y posiciones de comunicación», en Landowski, 1993, pp. 113-137). 
se juega la producción de la risa. El Ca debe hacer coexistir, en simultáneo, la impostación dramática de la canción con la lucha por mantenerse en la posición de blanco de la mirada. Lucha esta que, en términos de interacción, equivale a un denodado reajuste que busca, en vano, reprogramar, estabilizar esa extraña «no puesta» en escena. El Ca, con sus gestos exagerados, «da cuerpo» a una canción lánguida, trémula, de talante triste, melancólico, pero su presencia en escena es «ausentificada», debilitada por el Op; lo que, por contraste, resalta su ostensión y hasta su descaro; en la confrontación misma, queda como un exhibicionista frustrado. Veamos.

La primera estrofa, cantada en el escenario, instala a un yo que pide a un tú que no lo deje. Eso indica que túl aquílahora lo está dejando. En su tensión misma, esa manipulación es una invocación a «oublier le temps / des malentendus / et le temps perdu / a savoir comment». De inmediato, cuando insiste en la invocación «oublier ces heures / qui tuaient parfois», empieza la dinámica de abandono del círculo de luz al Ca perfectamente coordinada con el movimiento de apertura exterior de su brazo derecho. Ese rítmico desajuste, lo lleva a accidentarse, esto es, a tropezar con un poste... justo cuando la canción dice «a coups de porquoi / le coeur du bonheur».

En efecto, el Op ha movido el haz de luz a la izquierda del encuadre como concentrándose en el movimiento de brazo del $\mathrm{Ca}$, pero desenfocando su cuerpo mismo. Obliga así al Ca a moverse hacia su derecha. Luego del choque con el poste, queda a oscuras hasta que vuelve a alcanzar el haz de luz. El Op ha hecho algo con un objeto (el rayo de luz); en realidad, ha maniobrado con él de tal modo que dicho objeto se convierte en sujeto manipulador del Ca. Esa manipulación ha desprogramado al Ca respecto a lo que se espera del programa «normal» de representación, $\mathrm{y}$, a la vez, ha desajustado su puesta en acto de tal modo que le ocurra un accidente, esto es, una coincidencia de su movimiento con la ubicación del poste, el cual, en términos posicionales, se convierte en obstáculo. La concomitancia de la súplica «ne me quitte pas» con los apagones o con los «quites» del rayo de luz reorienta el sentido de la canción y del espectáculo mismo, de tal modo que la eficacia de la risa así producida llega a ser independiente de si el enunciatario sabe o no francés, es decir, de si conoce o no el contenido de la canción. De ese modo, si en la canción el yo-masculino se dirige a un tú-femenino pidiéndole insistentemente que no lo abandone, en la representación somática, escénica, el Ca parece dirigirse al haz de luz mismo, y por ende al Op, que, de facto, lo está dejando constantemente abandonado.

$\mathrm{Si}$ atendemos a la rección de lo enunciado en la actuación del Ca sobre lo enunciado en la canción, notamos que la manipulación del Ca fracasa, en escena, por la presencia del desajuste con la luz maniobrado por el Op, quien osten- 
ta así su poder. Ese desajuste anticipa, a su vez, lo que debe ser, en el relato de la canción, el posible rechazo del túfemenino a la súplica manipulatoria del yo-masculino: los tiempos de los malentendidos, con sus golpes incluidos, no se han olvidado, están presentes. Se anuncia así un drama de la contradicción: al concluir la estrofa el Ca suplica el primer «ne me quitte pas» y la luz, simplemente, se quita. En la primera repetición de la súplica, en penumbra o claroscuro, se llega a ver la mirada incómoda, amenazante, hacia arriba, del Ca al Op, tan estéril como su ruego. Otra vez, la manipulación rechazada se manifiesta en la oscuridad reinante cuando escuchamos la última súplica de la estrofa «ne me quitte pas».

Pero la marcha de esta representación va a tener su ritmo: el Ca se recuperará varias veces, hará denodados esfuerzos y volverá a alcanzar, una y otra vez, el haz de luz. En efecto, una vez producido el accidente, se darán, sucesivos, el reajuste y la reprogramación mediante los cuales el Ca volverá, aun cuando sea por pocos segundos, a ocupar el centro de la circunferencia luminosa. Ese paso breve de la oscuridad a la luz condensará, en diversas configuraciones, efectos cómicos.

En lo que respecta a la interacción del Ca con el Op, podemos decir que, a pesar de las súplicas insistentes contenidas en la canción y de la tónica significativa de sus gestos y movimientos - como por ejemplo, cuando interpela al Op con una mirada de bronca-, el Ca fracasa en ese intento amenazante de manipular al Op para encarrilarlo en un programa «normal» de representación acorde con la dignidad que debiera tener el enunciado cantado.

En la segunda estrofa el yo-masculino cambia su estrategia manipulatoria: ahora recurre a la promesa. Propone hacer cosas míticas, heroicas, ofrece «des perles de pluie / venues de pays / oú il ne pleut pas», hermosa figura antitética que lleva la contradicción a una depurada expresión poética..., mientras en escena la contradicción se vive, se hace carne: el $\mathrm{Ca}$, cuya voz es la materia misma de la canción (que crea al personaje de la misma), ha quedado a oscuras en el tercer verso, por lo que, de nuevo, persigue y alcanza al rayo luminoso.

No bien alcanza la luz, el Ca proclama «je creuserai la terre / jusqu'après ma mort / pour couvrir ton corps d'or et de lumière». Del «agua» de las «perlas de lluvia» a la «tierra» transmutada alquímicamente, por una especie de Orfeo, en oro y luz, con el fin de cubrir el cuerpo de la amada y convertirla en diosa ${ }^{12}$. En el momento en

12 El oro, parangón de los metales, es reconocido como el más precioso y perfecto, pues ostenta el brillo de la luz. Ígneo, solar, real, divino, carne de los dioses, símbolo del conocimiento, de la transformación divina del hombre (Chevalier \& Gheerbant, 2003, pp. 784-786). 
que canta «lumière» sobreviene otro apagón; ahora la antítesis se da entre diferentes niveles de cohesión del texto. Mientras el yo-masculino desembraga una imagen de brillo, el Op maniobra para que en plena oscuridad quede un tenue círculo de luz no ocupado, justo cuando el Ca promete «je ferai un domaine / où l'amour será roi / où l'amour será loi». No obstante, el Ca llega al círculo de luz y es enfocado cuando clama «où tu seras reine». De nuevo la antítesis: promete a futuro un dominio virtual, un reino de amor, pero no logra estabilizar ni actualizar dominio alguno en escena.

La concomitancia del apagón con las súplicas del $\mathrm{Ca}$, «ne me quitte pas», crea las condiciones de oscuridad para una nueva escena: el haz de luz ya lo ha desairado una vez más dejándolo a oscuras, esto es, desajustándose de él; ahora enfoca una escalera, que parece ser la de la bajada a platea. La maniobra de Op con el haz de luz, a efectos del espectáculo, equivale a una desprogramación que crea las condiciones para que, de nuevo, la posición del círculo de luz manipule al cantante sumiéndolo en un desajuste tal que rueda por esa escalera, esto es, lo lleva a sufrir un accidente... del cual se reajusta rápidamente acomodándose sentado en la grada y aprovechando la pausa de la canción para, con aire seductor, lanzar graciosos y coquetos guiños a alguien de platea. La ajustada interacción con la risa de los asistentes llega aquí a un pico de intensidad. La apurada prueba: reajuste, seducción y reprogramación de Ca frente a las maniobras de Op se va a desvanecer pronto con otro quite de luz.

La tercera estrofa comienza, entonces, con un súbito apagón simultáneo al enunciado «ne me quitte pas», el cual desembraga un tenue círculo de luz «desocupado» en la zona alta, derecha, del encuadre. Cuando el círculo crece y se pronuncia más, llega, por debajo, sumido en la penumbra, el Ca, quien se pone a saltar varias veces para ajustarse a la posición de la luz. Esa acción es concomitante con un nuevo crecimiento tónico de la risa del público. Eso ocurre mientras en el enunciado de la canción se mantiene la promesa «je t'inventerai / des mots insensés / que tu comprendras». La «insensatez», como predicación contenida en el enunciado de la canción para calificar las «palabras», queda de algún modo debilitada por la forma no muy sensata de cantar-saltar que el Obs contempla en la escena. Luego, cuando el Ca vuelve a prometer «je te parlerai / de ces amants-là», de inmediato vuelve a golpearse y se lleva la mano derecha a la cabeza mientras canta «qui ont vu deux fois / leurs cœurs s'embraser» y... vuelve a quedar a oscuras. De nuevo la antítesis: la figura de fuego, de luz, en el enunciado de la canción; e, ipso facto, en escena, la oscuridad y el haz de luz que apunta a unas cortinas de bastidores por donde se desplaza alguien extraño al espectáculo, mientras la canción dice «je te raconterai / l'histoire de ce roi/ mort de n'avoir pas / pu te rencontrer». El Ca llega justo 
para el último verso, pero es evidente que el Op no quiere saber nada con él: al «encuentro» enunciado corresponde el «desencuentro» actuado. De inmediato el Op desvía la mirada del Obs a la platea desairando al Ca: este, a oscuras, sin poder ser visto, suplica «ne me quitte pas / ne me quitte pas / ne me quitte pas / ne me quitte pas».

La mira luminosa aparece enfocando a un grupo de espectadores en la platea: una niña, un niño, una señora y un señor. Están en tensión de espera, pues la luz los alumbra... hasta que llega el Ca, se sienta en las rodillas de la niña e inicia su canto (ajuste perfecto, instantáneo, del Ca y del Op, estallido de risas), la abraza cariñosamente y la hace sonrojarse: el Ca se reprograma, exhibe un ajuste perfecto con el Op, manipula a la niña, se ajusta a su presencia sensible, todo en un solo acto. La cuarta estrofa, que acompaña ese acto, es de tónica enunciva: «On a vu souvente / rejaillir le feu / d'un ancien volcan / q'on croyait trop vieux». De nuevo, la figura del fuego salpicando, de la luz apareciendo cuando ya no se la esperaba («en un antiguo volcán»); igual que el $\mathrm{Ca}$ aparece inesperadamente en el regazo de la niña; a quien, por cierto, hace prenderse, sonrojarse. Pasa luego a sentarse en las rodillas de una mujer mientras canta «Il est paraîtil / des terres brûlées»: el cambio de la «niña» a la «adulta» es, en términos semisimbólicos, correlativo al cambio del «fuego» a la «ceniza». Cuando el Ca trata de sentarse muy brevemente en las rodillas del adulto y hace un gesto de repugnancia, como que algo le hinca por abajo, estalla paroxísticamente la risa del público. El juego semisimbólico apuntala la analogía del «fuego» con el aumento superlativo del «trigo», símbolo áureo del alimento, figura vegetal, primaveral, de luz: «donnant plus de blé / qu'un meilleur abril». El Ca sale ágilmente del regazo del adulto, mientras cambia de tiempo: «Et quand vient le soir». Ese doble cambio (de postura y de figura temporal) lo hace perder el paso, caer de pies y manos al suelo y reincorporarse rápidamente cantando: «pour qu'un ciel flamboie», en un evidente ajuste del recorrido corporal, de «abajo» a «arriba» con el paso de la «tierra» al «cielo». No obstante, el Op ya está haciendo de las suyas; cuando el Ca exclama: «le rouge et le noir / ne s'épousent-ils pas», ya ha sobrevenido un ambiente oscurecido, en el que apenas se notan, en lo que debe de ser el suelo del escenario, tres elipses de luz y breves reflejos del Ca caminando rápidamente persiguiendo esas formas luminosas. La lírica de la canción, contrastada con la actuación, cobra ribetes semisimbólicos: el paso de lo «femenino» a lo «masculino» es correlato del paso del «día» a la «noche» y de la «tierra» al «cielo», pero todo para perpetuar el «brillo2 gracias a la separación del «rojo»y del «negro»: pero cuando el Ca habla de colores ha sobrevenido ya la oscuridad. Esa escena de la platea es la que más largo tiempo coordina o ajusta sensiblemente la performance del Ca con la del Op, curiosamente, en un espacio 
que no es propiamente el escenario. El retorno al escenario es la vuelta plena a la descoordinación de Ca y Op. Su culminación.

Esa persecución del Ca a las elipses luminosas del suelo ya tiene todos los contornos de un auténtico desbarajuste: las pequeñas elipses giran y obligan al cantante a perseguirlas en penumbra mientras clama «ne me quitte pas / ne me quitte pas / ne me quitte pas». La fricción semántica de la languidez de la canción con la agitación de las correrías da por resultado esa chispa casi tragicómica: el Op juega con un poder que somete perversa y cruelmente al Ca. De ahí que, por momentos, como después de esa tercera súplica, el Ca reacciona mirando rabioso hacia arriba, a quien no lo quiere mirar, buscando la confrontación cara a cara. Pero esa amenaza deja el plano afectivo cognitivo de la mirada y va a pasar al plano pragmático del acto. Después de la cuarta súplica, la luz, en la coda musical de la estrofa, se ha quitado y, repentinamente, se prende de nuevo para que el Obs sorprenda al Ca en una actitud de apuntar con una pistola grande hacia arriba, hacia la fuente de luz, con la «evidente» intención, desesperada, de matar al Op, es decir, de desprogramarlo para librarse de ese su insistente y molesto contraprograma e iniciar, liberado, un nuevo programa.

Ese virtual Ca asesino se ve sorprendido por la mirada de luz, mira la pistola y la esconde rápidamente tras su cuerpo. Por supuesto que eso impli- ca el ascenso a otro pico de intensidad en esa comunión estésica representada por las fuertes risas mezcladas con los aplausos que las envuelven debilitando, en horizonte, los dos primeros versos de la quinta estrofa: «ne me quitte pas / je ne vais plus pleurer».

La estrategia persuasiva contenida en el enunciado cantado, como veremos, apunta a una aminoración de la presencia del yo-masculino, quien se conforma con solo mirar bailar, mirar sonreír y escuchar al tú-femenino. Incluso, con tal de impedir el abandono, ese yo-masculino está dispuesto a ser objeto del tú-femenino, hasta el extremo de llegar convertirse en su sombra. En términos pasionales, diríamos que estamos ante una estrategia desesperada.

Hacia el tercer verso el Obs contempla, en contrapicado, en el círculo de luz segmentos de los postes dorados que convergen hacia arriba. Luego de tomar cierta distancia, la mirada se desliza lentamente desde arriba hacia abajo, mientras escuchamos «je ne vais plus parler / je me cacherai là / A te regarder / danser et sourire». Si bien el yo-masculino anuncia que se va a esconder, en el último verso el Ca que lo representa es sorprendido por esa mirada que se desliza de arriba hacia abajo, trepado en uno de los postes... pero la mirada de luz se detiene apenas unos pocos segundos en él, quien conserva la disposición de cantar (mano izquierda en el micro), junto con la de trepar (mano derecha y piernas prendidas al 
poste): «Et a t'écouter / chanter et puis rire / laisse-moi devenir / l'ombre de ton ombre». La luz sigue bajando y ese nuevo desajuste lo obliga a desprogramar la subida y reprogramar la bajada; en el tercer verso el haz de luz lo abandona y lo lleva al extremo de llegar al suelo $y$, justo al cantar «l'ombre de ta main, l'ombre de ton chien» se ve obligado a andar a gatas. El Obs lo ve gateando alternativamente de un círculo a otro, los cuales giran, van y vienen; el Ca se levanta para perseguirlos caminando hasta que, luego de clamar «ne me quitte pas», da un paso y con todo su peso cae a un hueco que se abre en el piso. Luego de ese accidente, culmina su performance desde la penumbra sacando la cabeza por el hueco... Por fin, cuando está quieto, la mirada de luz se detiene en su rostro para que el Obs pueda verlo cantando los dos últimos versos «ne me quitte pas / ne me quitte pas», mientras los aplausos ensordecedores envuelven la escena.

Este no ha sido cualquier $\mathrm{Ca}$, ha sido un Ca en apuros que ha tenido que desplegar una panoplia de tomas de posición y de actitudes desesperadas para ser reconocido y ha terminado «bajo tierra». Sumido en un desorden que lo desprograma y desajusta, se ha entreverado en un encadenamiento de torpezas y fallidos pasos al acto, se ha visto obligado a moderar sus miras y a ser tragado por el doble sentido, cual bufo errante llevado a reiniciar sin cesar, desde el Mí-carne, su memoria de Ca.
La última toma, en contrapicado, revela el misterio de la identidad del Op: la mirada se dirige a una presunta operadora de luz, el Obs recién la identifica figurativamente, es una mujer extravagantemente vestida de rosado con borlas azules, de pelo crecido y ensortijado, muy coherente con la hexis circense, que ríe jocosamente y aplaude luego de haber «entorpecido» la performance del Ca. De inmediato se voltea y muestra su calzón de bobos disponiéndose a retirarse de la torre de luz.

El contraste entre el melodrama contenido en el discurso cantado y las cómicas peripecias (o actitudes desaforadas - gags-) del discurso somático «en escena», que serían su plano de la expresión, crea las condiciones para esa recurrente ruptura semiótica de isotopías de la que brota una manipulación cómica eficaz: el hacer reír haciendo quedar en ridículo al protagonista, contrastando su estrambótica performance con la del modelo del chanteur elegante y distinguido, «imagen-meta» ya conocida, potencial, construida en perspectiva (Sí-ipse).

Ahora bien, ya no desde la pertinencia del simulacro puesto en escena, sino desde la de un «número de circo», entendiendo «circo» como marco contextual o, más bien, interdiscursivo, como no podía ser de otro modo tratándose del Cirque du Soleil o de alguna otra compañía de su nivel, se reconoce el rol de bufón o saltimbanqui, adscri- 
to al género parodia. El cuerpo se ha especializado y restringido. En cuanto actante «repite su lección», aplica su guion. Asistimos audiovisualmente al perfecto ajuste de unos cómicos desajustes; o, en otros términos, a una notable performance programada y realizada con tal precisión y cuidado que conmueve, en este caso haciendo reír; es decir, manipulando estésicamente. Desde esa perspectiva, los «accidentes» no son accidentes. No importan como tales ( $v$. gr. los dibujos animados), ya que no revisten consecuencias trágicas, sino cómicas. En efecto, somos testigos de un «número» decididamente eficaz: todo está planeado y logrado con tal sincronía de movimientos y tal belleza interactiva que nos lleva a admitir, sin más, que, en especial, la programación y el ajuste no solo se pueden retroalimentar, sino también complementar amenamente en un todo de sentido —dominado en este caso por el Síídem, fiel al código circense- .

Pero esa estrategia manipulatoria de hacer reír se multiplica y refuerza mediante un contagio estésico desplegado como ajuste: en efecto, la puesta en escena de la risa de los espectadores figurativizados (en el espectáculo) como asistentes (al espectáculo) busca inducir la risa del enunciatario; este se reirá no solo por lo que ve, sino también y, sobre todo, por lo que oye, la risa del público. La producción de la risa articula, pues, un dispositivo de puesta en escena de los desajustes entre el cantante, de un lado, y el ope- rador/observador, del otro, con los consecuentes accidentes del primero de ellos; pero, además, por contagio, eleva exponencialmente la escena de las jocosas peripecias al sumarle la presencia constante de unas carcajadas que harán reír al espectador con la risa del asistente.

\section{Para terminar: dos inquietudes}

Nos preguntamos si el punto de vista de la sintaxis tensiva de la interacción, aquí apenas esbozado, de orden figural, podría superar, sin «reemplazar», al de la sintaxis narrativa de la interacción, de orden figurativo. Por lo demás, esas «zonas de tránsito» $\mathrm{O}$ «medios caminos entre» los «cuatro regímenes» nos llevan a pensar si nuestro «refinado» modelo, atraído no tanto por la selección como por la mezcla de regímenes intermedios, no apunta más bien a esos grados del intervalo en los que encontramos toda una gama de interacciones sin nombre.

\section{Referencias}

Chevalier, J. \& Gheerbrant, A. (2003). Diccionario de símbolos. Barcelona: Hachette.

Deleuze, G. (2002). Diferencia y repetición. Buenos Aires: Amorrortu.

Fontanille, J. (2008). Soma y sema. Figuras semióticas del cuerpo. Lima: Universidad de Lima, Fondo Editorial. 
Fontanille J. (2009). Comentario. En Landowski, E., Interacciones arriesgadas. Lima: Universidad de Lima.

Landowski, E. (1993). La sociedad figurada. Ensayos de sociosemiótica. México: Fondo de Cultura Económica. [La société réfléchie. París: Seuil, 1989].

Landowski, E. (1997). Présences de l'autre. París: PUF. [Presencias del otro. Lima: Universidad de Lima, 2007].

Landowski, E. (2004). Passions sans nom. Essais de socio-sémiotique III. París: PUF.
Landowski, E. (2009). Interacciones arriesgadas. Lima: Universidad de Lima. [Landowski, E. (2005). Les interactions risquées. Nouveaux Actes Sémiotiques, 101, 102, 103. Limoges: PULIM].

Serres, M. (2011). Variaciones sobre el cuerpo. Buenos Aires: Fondo de Cultura Económica.

Zilberberg, C. (2006). Semiótica tensiva. Lima: Universidad de Lima, Fondo Editorial. 